\title{
Del infierno al purgatorio: empleo, salarios y distribución del ingreso en el Gran Rosario (2003-2007)
}

\section{Carlos Crucella}

Carlos Crucella es investigador del Consejo de Investigaciones de la Universidad Nacional de Rosario, profesor titular de Economía III, Facultad de Ciencia Política y Relaciones Internacionales (UNR).

Mail: crucella-robin@arnet.com.ar

\section{resumen}

El presente trabajo analiza el comportamiento del empleo y los salarios en uno de los dos aglomerados urbanos más grandes del interior del país, entre la segunda mitad del año 2003 y la primera parte de 2007. Su propósito es dar cuenta del impacto que los cambios macroeconómicos registrados durante ese período han tenido sobre la evolución del mercado de trabajo local, a través del análisis de una selección de variables consideradas relevantes a tal efecto, cuya trayectoria permite comprobar un significativo incremento del empleo, un aumento de los salarios reales y una mejora en la distribución funcional de la riqueza generada en la región.

\section{summary}

This article analyses the behaviour of employment and salaries in one of the two most populated urban inland areas of the country between the second half part of 2003 and the first one of the year 2007. Its purpose is to show the impact the macroeconomics had on the evolution of the local labour market, focusing on some relevant selected variables. According to them, employment has remarkably increased and real wages have undergone a noticeably improvement as well as income distribution in the region.

\section{palabras clave}

Argentina / Gran Rosario / empleo / salarios / distribución del ingreso

\section{keywords}

Argentine / Rosario Area / employment / wages / income distributions 


\section{A modo de prólogo}

El presente artículo forma parte de una investigación más amplia que se extiende desde la segunda mitad de 2003 hasta igual período de 2007, cobertura temporal que obedece a dos razones de distinta índole.

La primera, de naturaleza operativa, se vincula con el cambio metodológico introducido en la Encuesta Permanente de Hogares a partir del $3^{\circ}$ trimestre de 2003 (INDEC, 2003a y 2003b), el cual, lamentablemente, imposibilita la comparación de la información suministrada desde ese momento con la correspondiente a cualquier período anterior. La segunda, más sustantiva, remite al propósito de analizar el impacto que el notable crecimiento que experimentó la economía argentina durante los cuatro años de la administración $\operatorname{Kirchner}^{1}$ ha tenido sobre el mercado de trabajo urbano a nivel nacional, territorial y local.

Dado que, a raíz de la situación conflictiva que afecta al INDEC, la última información disponible a la fecha (Base Usuaria Ampliada) corresponde al $1^{\circ}$ trimestre de 2007, se ha estimado conveniente dar a conocer los resultados obtenidos para el Aglomerado Gran Rosario, aún sabiendo que la buena práctica aconseja no utilizar ondas diferentes para el estudio de la evolución de las variables ocupacionales, con el propósito de evitar la incidencia de los eventuales efectos que el factor estacional pudiera tener sobre las mismas. ${ }^{2}$ A causa de los motivos expuestos, en este caso se ha optado por dejar de lado esa sana prescripción, razón por la cual se recomienda tener en cuenta esta "trasgresión metodológica" a la hora de analizar la evidencia empírica. Finalmente, cabe señalar que, por razones de espacio, no ha sido posible realizar un estudio del comportamiento de las variables en el interior del período, el cual ha debido reducirse a las variaciones entre los extremos del mismo.

\section{Introducción}

El Gran Rosario, como cualquier unidad territorial subnacional, es un área económicamente abierta, cuya apertura se refleja en la marcada incidencia del régimen macroeconómico en la dinámica de su proceso productivo y, consecuentemente, en el comportamiento de su mercado de trabajo (Municipalidad de Rosario, 1971: 13).

Por lo tanto, el signo y la intensidad de la evolución de su nivel de actividad económica, así como la composición sectorial de su producto y, en general, las características de su patrón de crecimiento presentan un bajo nivel de autonomía respecto de las condiciones macroeconómicas imperantes. Esta dependencia, sin embargo, no es (necesariamente) absoluta, ya que el impacto de estas últimas sobre el perfil productivo y ocupacional de una región se ve mediatizado por ciertos atributos "idiosincrásicos" (económicos, sociales, políticos e institucionales) que pueden acentuar o morigerar los efectos de un determinado régimen de acumulación aunque, difícilmente, alterar el signo que el mismo le impone a la economía nacional en su conjunto.

En consecuencia, aún cuando el deterioro de la situación laboral de la región constituye un fenómeno de larga data, cuyo origen se remonta a mediados de la 
década del $70^{3}$, con la ruptura del patrón de desarrollo de industrialización por sustitución de importaciones (ISI) ${ }^{4}$, el mismo experimentó un notable agravamiento a lo largo del período de vigencia del régimen de convertibilidad, durante el cual se destruyeron puestos de trabajo preexistentes, en tanto el número de desocupados y subempleados horarios aumentó un 174 y 145\% respectivamente (Crucella, 2003), empeorando de manera directa e indirecta (Frenkel, 2002: 37-38) la de por sí inequitativa distribución del ingreso existente a comienzos de los noventa. A partir del cambio de las condiciones macroeconómicas que tuvo lugar en 2002, a fines de ese año comenzó un proceso de crecimiento económico ininterrumpido de una magnitud inédita, que impactó de forma particularmente positiva en el nivel de actividad y, consecuentemente, en la evolución del mercado de trabajo del Gran Rosario que, de este modo, comenzó a dejar atrás el abismo en que había caído en el período inmediatamente posterior a la devaluación. ${ }^{5}$

\section{La evolución de la situación ocupacional}

Entre los extremos de los tres años y medio analizados la Población Económicamente Activa creció el 4,6\%, lo que equivale a la incorporación neta de unas 24.000 personas al mercado de trabajo de la región.

Dado que en el mismo período la población total sólo se incrementó el 1,4\% y aquella parte de ella que cuenta al menos con 10 años de edad (que constituye el subconjunto etario sobre el cual es dable estimar la PEA) se mantuvo prácticamente inalterada (en rigor, se redujo en algo más de 3.000 habitantes), la tasa de actividad global aumentó del 44,5 al 45,9\%, y la correspondiente a este último grupo (que es, stricto sensu, la más apropiada metodológicamente para analizar este indicador) pasó del 51,4 al 53,9\%.

Cuadro I

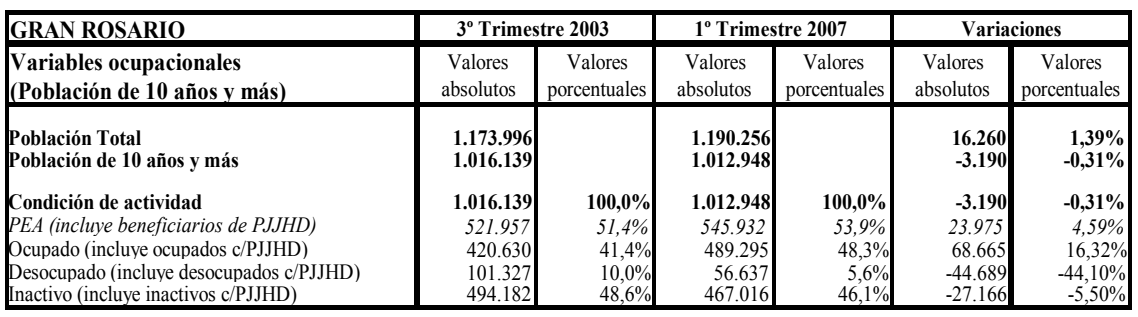

Fuente: Elaboración propia a partir de la EPH continua (Base Usuaria Ampliada)

A su vez, el número de ocupados se expandió en una proporción notablemente mayor (16,3\%), lo que representa el ingreso de alrededor de 68.600 personas al circuito productivo, cifra que equivale a la incorporación neta de más de 1.600 personas por mes en promedio.

Como resultado de esta evolución, la tasa de empleo global se incrementó 5 puntos porcentuales (de 35,8 en el $3^{\circ}$ trimestre de 2003 a $41,1 \%$ en el primero 
de 2007), en tanto la específica de la población de 10 años y más lo hizo en unos 7 p.p. ( 41,4 y $48,3 \%$ respectivamente).

\section{Cuadro II}

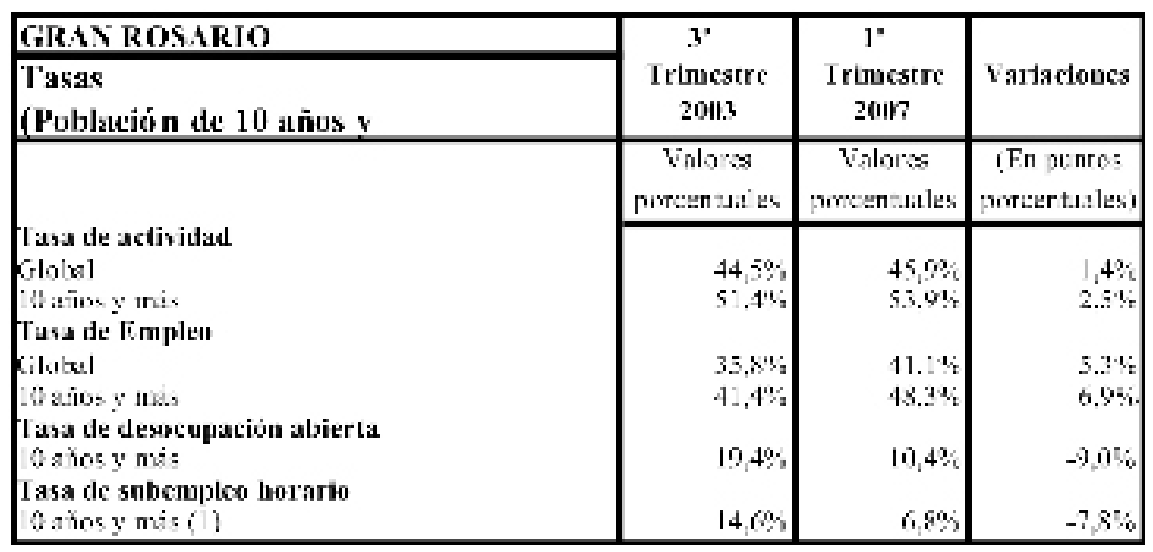

(1) Redistribuidos los ocupados que no trabajaron la semana de referencia.

Fuente: Elaboración propia a partir de la EPH continua (Base Usuaria Ampliada)

En consecuencia, la creación de nuevas oportunidades laborales ${ }^{7}$ no solo alcanzó para absorber a la totalidad de los ingresantes a la fuerza de trabajo sino que, además, permitió incorporar a la actividad económica a casi 45.000 desocupados, lo que redujo su número en un $44,1 \%$. Este fenómeno, unido al crecimiento de la PEA, explica la caída de la tasa de desocupación del 19,4 al 10,4\%, es decir, a poco más de la mitad del valor registrado en el $3^{\circ}$ trimestre de 2003.

\section{La incidencia de los planes de empleo}

El aumento del número de puestos de trabajo no puede ser atribuido a un incremento de los beneficiarios del Plan Jefes y Jefas de Hogar Desocupados, ya que su cantidad total ${ }^{8}$ se redujo el $36,2 \%$ en ese período, pasando de unos 32.000 a alrededor de 20.000, en tanto los correspondientes exclusivamente a los ocupados lo hicieron en una proporción aún mayor (65\%), alcanzando en 2007 al 2,1\% de las personas que habían trabajado en la semana de referencia frente al 7,1\% que representaban en 2003. Lo expuesto significa que en ese período unas 19.500 personas consiguieron insertarse laboralmente en distintas actividades, dejando de depender de la asistencia que brinda el PJJHD.

Por lo tanto, cabe afirmar que durante dicho lapso de tiempo tuvo lugar una generación de oportunidades laborales "genuinas", que no respondió a la acción directa del Estado a través de planes de empleo transitorio, sino a la evolución de la demanda de mano de obra de la región. 


\section{Cuadro III}

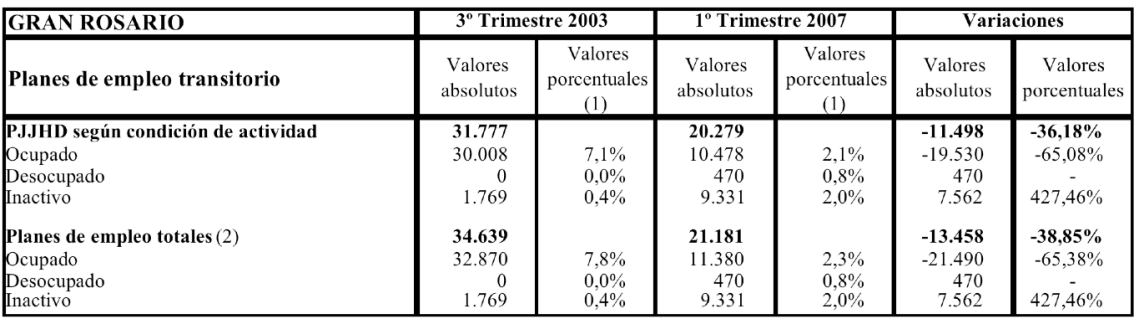

(1) Como porcentaje de los respectivos totales.

(2) Incluye, además del PJJHD, a otros de características similares.

Fuente: Elaboración propia a partir de la EPH continua (Base Usuaria Ampliada)

\section{Características de la evolución del empleo}

\section{a) Las ocupaciones de jornada completa y parcial}

El aumento del número de ocupados abarcó exclusivamente a aquellos de tiempo completo (35 y más horas semanales), en tanto los de jornada parcial (voluntaria e involuntaria) experimentaron una disminución del 11,4\% (equivalente a la desaparición de unas 19.000 ocupaciones de extensión horaria reducida, es decir, de menos de 35 horas hebdomadarias).

\section{Cuadro IV}



(1) Redistribuidos los ocupados que no trabajaron la semana de referencia.

(2) Ocupados que trabajaron menos de 35 horas semanales, desean trabajar más horas y están disponibles para hacerlo.

(3) Ocupados que trabajaron entre 35 y 45 horas semanales o que, habiendo trabajado menos de 35 horas hebdomadarias, no desean aumentar su carga horaria semanal o no se encuentran disponibles para hacerlo.

(4) Ocupados que trabajaron más de 45 horas semanales.

Fuente: Elaboración propia a partir de la EPH continua (Base Usuaria Ampliada) 
La disminución de la cantidad de trabajadores de tiempo parcial que tuvo lugar en este período estaría reflejando, en similares proporciones, un doble fenómeno que, en conjunto, pone de manifiesto una evolución positiva del perfil del empleo en la región, toda vez que, en última instancia, se traduce en una disminución de la subutilización horaria de la mano de obra. Por una parte, se observa un acentuado tránsito de la condición de ocupados de jornada reducida involuntaria a la de trabajadores de tiempo completo y, por la otra, una transformación de ocupados de tiempo parcial que desean trabajar más horas (subocupados horarios) en aquellos que no desean hacerlo 9 (ocupados horarios plenos), fenómeno plausiblemente asociado a mejoras en sus ingresos y/o en los de su grupo familiar.

\section{b) El empleo público y privado}

La totalidad de la creación neta de puestos de trabajo corresponde al sector privado, que durante este período generó cerca de 100.000 nuevas oportunidades laborales, las que equivalen a un aumento de su volumen de ocupación del 30\% vis-à-vis el comportamiento opuesto registrado por el sector público -que experimentó una reducción del número de trabajadores proporcionalmente similar pero que, debido a su menor peso en la estructura ocupacional de la región, representan la desaparición de algo más de 23.000 puestos de trabajo-, fenómeno plausible de ser explicado mayoritariamente por la disminución de unos 21.500 ocupados beneficiarios del conjunto de planes de empleo. ${ }^{10}$

El sector que nuclea las ocupaciones que no corresponden a ninguno de estos dos agrupamientos registró la expulsión de alrededor de 7.500 personas, cifra que representa una contracción de su nivel de empleo entre puntas cercana al $85 \%$, con lo cual se confirma que el Gran Rosario no sólo es un aglomerado con un marcado predominio del empleo privado sino que, además, en el período analizado, ese rasgo se ha acentuado, llegando a concentrar a comienzos de 2007 el 88,4\% del total de puestos de trabajo, proporción que tres años y medio atrás era del 79,1\%.

\section{Cuadro V}

\begin{tabular}{|c|c|c|c|c|c|c|}
\hline \multirow[t]{2}{*}{ GRAN ROSARIO } & \multicolumn{2}{|c|}{$3^{\circ}$ Trimestre 2003} & \multicolumn{2}{|c|}{$1^{\circ}$ Trimestre 2007} & \multicolumn{2}{|c|}{ Variaciones } \\
\hline & $\begin{array}{c}\text { Valores } \\
\text { absolutos }\end{array}$ & $\begin{array}{c}\text { Valores } \\
\text { porcentuales }\end{array}$ & $\begin{array}{c}\text { Valores } \\
\text { absolutos }\end{array}$ & $\begin{array}{c}\text { Valores } \\
\text { porcentuales }\end{array}$ & $\begin{array}{c}\text { Valores } \\
\text { absolutos }\end{array}$ & $\begin{array}{c}\text { Valores } \\
\text { porcentuales }\end{array}$ \\
\hline Ocupados según tamaño del establecimiento & 420.630 & $100,0 \%$ & 489.295 & $100,0 \%$ & 68.665 & $16,32 \%$ \\
\hline $\begin{array}{l}\text { Asalariados del servicio } \\
\text { Hasta } 5 \text { personas } \\
6 \text { a } 40 \text { personas } \\
\text { Más de } 40 \text { personas }\end{array}$ & $\begin{array}{r}23.889 \\
217.687 \\
100.840 \\
78.214\end{array}$ & $\begin{array}{r}5,7 \% \\
51,8 \% \\
24,0 \% \\
18,6 \%\end{array}$ & $\begin{array}{r}35.223 \\
204.094 \\
137.704 \\
112.274\end{array}$ & $\begin{array}{r}7,2 \% \\
41,7 \% \\
28,1 \% \\
22,9 \%\end{array}$ & $\begin{array}{r}11.334 \\
-13.593 \\
36.864 \\
34.060\end{array}$ & $\begin{array}{l}47,44 \% \\
-6,24 \% \\
36,56 \% \\
43,55 \%\end{array}$ \\
\hline
\end{tabular}

Fuente: Elaboración propia a partir de la EPH continua (Base Usuaria Ampliada) 


\section{c) Las ocupaciones según tamaño del establecimiento}

Un tercio de los empleos netos creados entre el $3^{\circ}$ trimestre de 2003 y el primero de 2007 se concentra en el conjunto de establecimientos de menor tamaño, aunque con comportamientos claramente diferenciados en el interior de ese grupo. En efecto, mientras el empleo en las unidades productivas que emplean entre 6 y 40 trabajadores se incrementó en un 36\% (37.000 nuevos puestos de trabajo), dando cuenta de más de la mitad de las inserciones laborales generadas en estos tres años y medio, las microempresas ${ }^{11}$ destruyeron más de 13.000 ocupaciones, no obstante lo cual siguen siendo las principales demandantes de mano de obra de la región.

Del conjunto de establecimientos, aquellos que ocupan más de 40 personas fueron los que registraron el mayor crecimiento del empleo en términos relativos $(43,6 \%)$, concentrando casi el $50 \%$ del aumento neto de oportunidades ocupacionales.

A su vez, el 16,5\% de las nuevas ocupaciones corresponde a actividades que se llevan a cabo en hogares (Servicio Doméstico), cuyo volumen se incrementó un $47 \%$. Dado que la evolución de este tipo de inserción laboral está fuertemente asociada a los ingresos de las unidades familiares, particularmente a las pertenecientes a los sectores medios y medios altos, este fenómeno podría tomarse, prima facie, como un indicador de la mejora experimentada por los mismos durante este período.

\section{d) La absorción de mano de obra según las ramas de actividad económica}

Alrededor de dos terceras partes de la generación neta de oportunidades laborales se concentró en el sector terciario - lo cual no resulta sorprendente dado que el mismo cobija a tres de cada cuatro ocupados de la región (más del 65\% si se excluye a los correspondientes al servicio doméstico)-, cuyo volumen de empleo se expandió un $14 \%$, variación porcentual que, en el caso de tomar solamente en cuenta a aquellos que no se desempeñan en tareas domésticas, se reduce a poco más del $11 \%$.

La construcción, por su parte, es la rama de actividad que experimentó el crecimiento proporcionalmente más elevado de personas ocupadas $(50,8 \%)$-fenómeno fácilmente asociable al boom edilicio que caracterizó principalmente a la ciudad cabecera de la región durante este período-, no obstante lo cual, sólo 22 de cada 100 nuevos puestos de trabajo corresponden a este sector y, a comienzos de 2007, menos del 10\% de las personas que trabajaban en el Gran Rosario lo hacían en el mismo.

Con unas 16.000 nuevas oportunidades laborales, que equivalen a un crecimiento del $25 \%$ respecto de las existentes tres años y medio atrás, la industria manufacturera da cuenta de casi uno de cada cuatro puestos de trabajo netos generados entre 2003 y 2007, en tanto el sector primario fue el único cuyo volumen de empleo experimentó un retroceso (del orden de 7.000 ocupados), que lo redujo al $40 \%$ del existente en 2003. ${ }^{12}$ 


\section{e) El crecimiento del empleo y las categorías ocupacionales}

Si bien la categoría que experimentó un incremento proporcionalmente más intenso fue la de los empleadores, es la evolución de los asalariados la que da cuenta (en exceso) del aumento del empleo, situación esperable debido a su mayor participación en la estructura ocupacional. En efecto, su crecimiento (unas 73.000 ocupaciones $^{13}$ en relación de dependencia), sobreexplica la totalidad de la generación neta de puestos de trabajo, seguido por el de los patrones, con cerca de 5.000 nuevas posiciones laborales.

El número de cuentapropistas, por su parte, registró un aumento apenas perceptible, en tanto la cantidad de trabajadores familiares sin remuneración experimentó una notable contracción, superior a las 10.000 ocupaciones, quedando reducido su volumen a alrededor de una tercera parte del correspondiente a 2003.

La evolución de estos últimos, además de ubicar su magnitud en un nivel de mayor correspondencia con una sensible mejora en la situación ocupacional del aglomerado (en 2003 su número era similar al de los patrones) $)^{14}$, podría encontrarse asociada, por una parte, a la disminución del empleo en microempresas -ya que es en ese tipo de establecimientos, cuando es de carácter familiar, donde es dable esperar una mayor concentración de esta categoría de trabajadores- y, por la otra, a las mayores posibilidades de ingresar como obreros o empleados a establecimientos de mayor tamaño.

En todo caso, el aumento del número de asalariados, que representaban en 2007 casi tres cuartas partes de los ocupados totales, es un síntoma auspicioso toda vez que resulta más acorde con la estructura ocupacional que es dable esperar de una economía con un cierto grado de desarrollo. Asimismo, su incorporación en calidad de ocupados en relación de dependencia en establecimientos del sector estructurado del aparato productivo debería, plausiblemente, traducirse en un incremento de la productividad media de la mano de obra así como en un mayor nivel y continuidad de los ingresos presentes y diferidos de estos trabajadores y en los beneficios asociados a este tipo de inserción laboral. ${ }^{15}$

\section{Cuadro VI}

\begin{tabular}{|c|c|c|c|c|c|c|}
\hline \multirow[t]{2}{*}{ GRAN ROSARIO } & \multicolumn{2}{|c|}{$3^{\circ}$ Trimestre 2003} & \multicolumn{2}{|c|}{$1^{\circ}$ Trimestre 2007} & \multicolumn{2}{|c|}{ Variaciones } \\
\hline & $\begin{array}{c}\text { Valores } \\
\text { absolutos }\end{array}$ & $\begin{array}{c}\text { Valores } \\
\text { porcentuales }\end{array}$ & $\begin{array}{c}\text { Valores } \\
\text { absolutos }\end{array}$ & $\begin{array}{c}\text { Valores } \\
\text { porcentuales }\end{array}$ & $\begin{array}{c}\text { Valores } \\
\text { absolutos }\end{array}$ & $\begin{array}{c}\text { Valores } \\
\text { porcentuales }\end{array}$ \\
\hline Asalariados "verdaderos" & 279.583 & $66,5 \%$ & 355.997 & $72,8 \%$ & 76.414 & $27,33 \%$ \\
\hline Asalariados "fraudulentos" & $\begin{array}{r}8.239 \\
15.776\end{array}$ & $2,0 \%$ & $\begin{array}{r}4.893 \\
20.647\end{array}$ & $1,0 \%$ & $\begin{array}{r}-3.346 \\
4.871\end{array}$ & $-40,61 \%$ \\
\hline
\end{tabular}

Fuente: Elaboración propia a partir de la EPH continua (Base Usuaria Ampliada)

\section{f) La evolución del empleo y la calificación de las tareas}

La calificación de la inserción laboral, variable que busca medir la complejidad de las tareas específicas desarrolladas en el marco de cada ocupación (INDEC, 1997b), muestra que si bien el aumento del número de puestos de trabajo abarcó a la totalidad de las categorías, la expansión productiva que ha venido teniendo 
lugar en la región durante los tres años y medio bajo análisis resulta, básicamente, demandante de operarios y empleados con algún grado de conocimiento de las tareas a desempeñar y, en menor medida, de profesionales, técnicos y, sobre todo, de trabajadores sin calificación.

En efecto, los puestos de trabajo que no requieren mano de obra calificada fueron los que experimentaron la expansión proporcionalmente más débil $(7,2 \%)$, si bien en valores absolutos; dado que su participación en la estructura ocupacional supera la correspondiente a los profesionales y técnicos en conjunto, se ubica en segundo lugar, detrás de los trabajadores de categoría operativa.

Esta situación confirmaría que el crecimiento económico experimentado por la región a partir de 2003 resulta escasamente demandante de puestos de baja calificación, lo que avalaría la conveniencia de implementar programas de capacitación dirigidos especificamente al tipo de tareas que requiere la estructura productiva, en base a compromisos de contratación de los beneficiarios por parte de las empresas de la zona, a fin de no desaprovechar las habilidades adquiridas en el programa, potenciándolas, a su vez, a través de su experiencia en los establecimientos (learning by doing).

\section{CuadroVII}

\begin{tabular}{|c|c|c|c|c|c|c|}
\hline GRAN ROSARIO & \multicolumn{2}{|c|}{$3^{0}$ Trimestre 2003} & \multicolumn{2}{|c|}{$1^{0}$ Trimestre 2007} & \multicolumn{2}{|c|}{ Variaciones } \\
\hline & $\begin{array}{c}\text { Valores } \\
\text { absolutos }\end{array}$ & $\begin{array}{c}\text { Valores } \\
\text { porcentuales }\end{array}$ & $\begin{array}{c}\text { Valores } \\
\text { absolutos }\end{array}$ & $\begin{array}{c}\text { Valores } \\
\text { porcentuales }\end{array}$ & $\begin{array}{c}\text { Valores } \\
\text { absolutos }\end{array}$ & $\begin{array}{c}\text { Valores } \\
\text { porcentuales }\end{array}$ \\
\hline $\begin{array}{l}\text { Ocupados según calificación de la tarea de la } \\
\text { ocupación principal }\end{array}$ & 420.630 & $100,0 \%$ & 489.295 & $100,0 \%$ & 68.665 & $16,32 \%$ \\
\hline Profesional & 33.866 & $8,1 \%$ & 37.721 & $7,7 \%$ & 3.855 & $11,38 \%$ \\
\hline Técnica & 65.598 & $15,6 \%$ & 71.696 & $14,7 \%$ & 6.098 & $9,30 \%$ \\
\hline Operativa & 209.240 & $49,7 \%$ & 259.907 & $53,1 \%$ & 50.667 & $24,21 \%$ \\
\hline No calificados & 111.926 & $26,6 \%$ & 119.971 & $24,5 \%$ & 8.044 & $7,19 \%$ \\
\hline Ocupados según nivel educativo alcanzado & 420.630 & $100,0 \%$ & 489.295 & $100,0 \%$ & 68.665 & $16,32 \%$ \\
\hline Sin Instrucción & 4.337 & $1,0 \%$ & 3.979 & $0,8 \%$ & -358 & $-8,26 \%$ \\
\hline Primaria Incompleta (incluye educación & 26.543 & $6,3 \%$ & 35.153 & $7,2 \%$ & 8.610 & $32,44 \%$ \\
\hline Primariä Completa & 113.772 & $27,0 \%$ & 111.284 & $22,7 \%$ & -2.488 & $-2,19 \%$ \\
\hline Secundaria & 54.262 & $12,9 \%$ & 70.406 & $14,4 \%$ & 16.143 & $29,75 \%$ \\
\hline Secundäria Completa & 85.198 & $20,3 \%$ & 117.715 & $24,1 \%$ & 32.517 & $38,17 \%$ \\
\hline Superior Incompleta & 59.634 & $14,2 \%$ & 65.222 & $13,3 \%$ & 5.588 & $9,37 \%$ \\
\hline Superior Completa & 76.884 & $18,3 \%$ & 85.536 & 17,5 & 8.652 & 11,25 \\
\hline
\end{tabular}

Fuente: Elaboración propia a partir de la EPH continua (Base Usuaria Ampliada)

Las dos categorías correspondientes a los niveles de complejidad e instrucción formal más elevados (profesional y técnica), si bien registran un crecimiento del empleo proporcionalmente más acentuado que el correspondiente a la mano de obra no calificada, dan cuenta de alrededor del 6 y 9\%, respectivamente, de las oportunidades laborales generadas en el período, en tanto esta última lo hace en cerca de un $12 \%$. En consecuencia, cerca de tres cuartas partes de los nuevos puestos de trabajo se inscriben en el nivel de calificación operativo, situación que estaría señalando que la expansión productiva que ha venido teniendo lugar en el Gran Rosario durante estos 42 meses, resulta básicamente demandante de operarios y empleados con algún grado de conocimiento de las tareas a desempeñar (sea adquiridas por capacitación previa y/o experiencia laboral equivalente), perfil 
ocupacional que, de mantenerse, podría terminar traduciéndose en un creciente nivel de subutilización cualitativa de la mano de obra ocupada.

En efecto, aceptando la existencia de un cierto grado de vinculación entre los niveles de calificación ocupacional y los de educación formal alcanzados, plausiblemente creciente a medida que los primeros aumentan, a las tareas de nivel profesional corresponderían personas que hayan completado sus estudios superiores (CABA, 2001: 150). En el período bajo análisis se registró una incorporación neta al circuito productivo cercana a los 9.000 trabajadores con esas características educativas, en tanto sólo se crearon menos de la mitad de puestos de trabajo que exigen ese nivel de instrucción, lo que -suponiendo que la totalidad de los mismos haya sido ocupado por personas con estudios terciarios completos ${ }^{16}$-implica que más del $50 \%$ de la mano de obra con las más elevadas credenciales educativas formales que consiguió trabajo a partir de 2003 lo hizo en tareas que implican, a priori, algún nivel de subaprovechamiento de las capacidades adquiridas en el sistema de enseñanza.

\section{g) La cantidad de horas semanales trabajadas}

Dado que el análisis convencional de la evolución del empleo se realiza a través de la variación del volumen de ocupados (que no necesariamente debe ser coincidente con el de ocupaciones o puestos de trabajo, ver supra), es habitual no tener en cuenta que -dada una determinada composición del producto y un cierto estado de la técnica en aplicación, generalmente invariables en períodos cortoslos cambios en el nivel de actividad económica no se reflejan en el número total de personas ocupadas sino en la cuantía total de horas de trabajo requeridas. La conversión entre ambas está determinada por el tiempo promedio que trabajan las primeras en la totalidad de sus ocupaciones, por lo tanto, en el corto plazo, una misma tasa de crecimiento del producto puede dar lugar a distintos volúmenes de empleo dependiendo de que aumente, disminuya o se mantenga invariable la carga horaria media por ocupado. A la inversa, todo aumento (disminución) de esta última tenderá a afectar negativamente (positivamente) el ritmo de generación de oportunidades de inserción laboral en el aparato productivo. ${ }^{17}$

\section{Cuadro VIII (1)}

\begin{tabular}{|c|c|c|c|c|}
\hline \multirow[b]{2}{*}{ GRAN ROSARIO } & \multirow{2}{*}{$\begin{array}{c}3^{\circ} \\
\text { Trimestre } \\
2003\end{array}$} & \multirow{2}{*}{$\begin{array}{c}\mathbf{1}^{\mathbf{o}} \\
\text { Trimestre } \\
2007\end{array}$} & \multicolumn{2}{|c|}{ Variaciones } \\
\hline & & & $\begin{array}{c}\text { Valores } \\
\text { absolutos }\end{array}$ & $\begin{array}{c}\text { Valores } \\
\text { porcentuales }\end{array}$ \\
\hline $\begin{array}{l}\text { Horas semanales promedio trabajadas en la } \\
\text { ocupación principal }\end{array}$ & 38,9 & 41,0 & 2,1 & $5,36 \%$ \\
\hline $\begin{array}{l}\text { Horas semanales promedio trabajadas en } \\
\text { ocupaciones de tiempo completo }\end{array}$ & 51,5 & 50,0 & $-1,5$ & $-2,98 \%$ \\
\hline $\begin{array}{l}\text { Horas semanales promedio trabajadas en } \\
\text { ocupaciones de tiempo parcial }\end{array}$ & 19,9 & 20,4 & 0,5 & $2,56 \%$ \\
\hline $\begin{array}{l}\text { Horas semanales promedio trabajadas en todas } \\
\text { las ocupaciones }\end{array}$ & 39,9 & 42,0 & 2,1 & $5,34 \%$ \\
\hline
\end{tabular}

(1) Solo los ocupados que trabajaron la semana de referencia.

Fuente: Elaboración propia a partir de la EPH continua (Base Usuaria Ampliada) 
En este sentido, se comprueba que el tiempo medio semanal que trabajan los ocupados de la región en su actividad principal se halla dentro de estándares aceptables, tanto a nivel internacional como regional (Crucella, 2006). Sin embargo, el incremento de 2,1 horas en promedio registrado entre puntas, estaría señalando la existencia en el mercado de trabajo local de una cierta propensión a enfrentar los mayores niveles de producción vía la prolongación de la jornada laboral en lugar de hacerlo a través de la incorporación de mano de obra adicional, lo que constituye una restricción a la capacidad de generar nuevas oportunidades ocupacionales a futuro.

\section{h) La antigüedad en el puesto de trabajo}

Por último, cabe señalar que el mayor crecimiento del empleo se dio en los ocupados cuya antigüedad en la ocupación principal va de más de uno a cinco años, lo cual estaría poniendo de manifiesto que su creación tuvo lugar en el marco del proceso de reactivación económica que ha venido experimentando el país desde mediados de 2002. La evolución de este segmento -cuyo volumen concentra siete de cada diez nuevas oportunidades laborales netas-, unida al incremento experimentado entre puntas por aquellos trabajadores cuya permanencia supera un lustro, esto es, los que se habrían incorporado al aparato productivo antes de esa fecha y aún conservan su inserción en el mismo, explica el 95\% del aumento neto del empleo generado durante el período, con lo cual a comienzos de 2007 la proporción de mano de obra con más de 12 meses de permanencia en su puesto de trabajo superaba el $75 \%$ de los ocupados totales.

\section{Cuadro IX}

\begin{tabular}{|c|c|c|c|c|c|c|}
\hline \multirow[t]{2}{*}{ GRAN ROSARIO } & \multicolumn{2}{|c|}{$3^{\circ}$ Trimestre 2003} & \multicolumn{2}{|c|}{$1^{\circ}$ Trimestre 2007} & \multicolumn{2}{|c|}{ Variaciones } \\
\hline & $\begin{array}{c}\text { Valores } \\
\text { absolutos }\end{array}$ & $\begin{array}{c}\text { Valores } \\
\text { porcentuales }\end{array}$ & $\begin{array}{c}\text { Valores } \\
\text { absolutos }\end{array}$ & $\begin{array}{c}\text { Valores } \\
\text { porcentuales }\end{array}$ & $\begin{array}{c}\text { Valores } \\
\text { absolutos }\end{array}$ & $\begin{array}{c}\text { Valores } \\
\text { porcentuales }\end{array}$ \\
\hline
\end{tabular}

Fuente: Elaboración propia a partir de la EPH continua (Base Usuria Ampliada)

\section{Empleo y flujos migratorios: una digresión respecto de la incidencia de la población originaria de la Provincia del Chaco en la situación ocupacional del Aglomerado}

Dado que desde hace ya algunos años se viene insistiendo acerca de la existencia de un flujo migratorio de cierta intensidad desde regiones limítrofes, especialmente la Provincia del Chaco, que por su magnitud afectaría negativamente, entre otros aspectos, las oportunidades de acceso a un puesto de trabajo de los habitantes nativos del Gran Rosario, se ha estimado oportuno recurrir a la información suministrada por la Encuesta Permanente de Hogares (EPH) a efectos de intentar llevar a cabo una estimación de la magnitud de este fenómeno. ${ }^{18}$ 
En el $1^{\circ}$ trimestre de 2007 el 17,4\% de la población del aglomerado de 10 y más años ${ }^{19}$ había nacido en otra provincia (porcentaje equivalente a unos 176.000 habitantes). Dado que sólo alrededor del 23\% de estos últimos (unas 40.000 personas) lo había hecho en el Chaco, su participación en el conjunto de la población del área alcanzaba apenas al $4 \%$.

De ellos, sólo unos 2.000 residían en esa provincia cinco años atrás, lo que implica que su arribo al aglomerado sólo habría incrementado en esa magnitud la población del Gran Rosario correspondiente a ese estrato etario desde principios de 2002.

\section{Cuadro X}

\begin{tabular}{|c|c|c|}
\hline \multirow[t]{2}{*}{ GRAN ROSARIO } & \multicolumn{2}{|c|}{$1^{\circ}$ Trimestre 2007} \\
\hline & $\begin{array}{c}\text { Valores } \\
\text { absolutos }\end{array}$ & $\begin{array}{c}\text { Valores } \\
\text { porcentuales }\end{array}$ \\
\hline Población de 10 años y más & 1.012 .948 & $100,0 \%$ \\
\hline Nacida en otra provincia & 175.974 & $17,4 \%$ \\
\hline Población de 10 años y más nacida en la Provincia del Chaco & & \\
\hline Proporción de los nacidos en otra provincia de 10 años y más & 40.121 & $22,8 \%$ \\
\hline Proporción de la población de 10 años y más & 40.121 & $4,0 \%$ \\
\hline Residentes en otra provincia 5 años atrás & 16.463 & \\
\hline Chaco & & \\
\hline Proporción de los residentes en otra provincia de 10 años y más & 2.036 & $12,4 \%$ \\
\hline Proporción de la población de 10 años y más & 2.036 & $0,2 \%$ \\
\hline Población Económicamente Activa & $\mathbf{5 4 5 . 9 3 2}$ & $100,0 \%$ \\
\hline Nacida en otra provincia & 100.797 & $18,5 \%$ \\
\hline PEA nacida en la Provincia del Chaco & & \\
\hline Proporción de la PEA nacida en otra provincia & 23.817 & $23,6 \%$ \\
\hline Proporción de la PEA de 10 años y más & 23.817 & $4,4 \%$ \\
\hline $\begin{array}{l}\text { PEA de residentes en otra provincia } 5 \text { años atrás } \\
\text { Chaco }\end{array}$ & 7.835 & \\
\hline Proporción de la PEA de residentes en otra provincia & 409 & $5,2 \%$ \\
\hline Proporción de la PEA de 10 años y más & 409 & $0,1 \%$ \\
\hline Ocupados & 489.295 & $100,0 \%$ \\
\hline Nacidos en otra provincia & 93.430 & $19,1 \%$ \\
\hline Ocupados nacidos en la Provincia del Chaco & & \\
\hline Proporción de los ocupados nacidos en otra provincia & 22.172 & $23,7 \%$ \\
\hline Proporción de los ocupados totales & 22.172 & $4,5 \%$ \\
\hline $\begin{array}{l}\text { Ocupados residentes en otra Provincia } 5 \text { años atrás } \\
\text { Chaco }\end{array}$ & 5.576 & \\
\hline Proporción de los ocupados residentes en otra provincia 5 años & 409 & $7,3 \%$ \\
\hline Proporción de los ocupados totales & 409 & $0,1 \%$ \\
\hline
\end{tabular}

Fuente: Elaboración propia a partir de la EPH continua (Base Usuaria Ampliada)

Del total de nativos del Chaco alrededor del $60 \%$ se encontraban incorporados al mercado de trabajo en 2007 (unas 24.000 personas, de las cuales sólo 400 no residían en la región hace 5 años). De ellos unos 22.000 se hallaban ocupados, con 
lo cual la proporción que representaban tanto en la PEA como en la ocupación del aglomerado se ubicaba ligeramente por encima de la correspondiente a su participación en la población (4,5\%), fenómenos explicables, en principio, por la tasa de actividad más elevada que suelen presentar los migrantes así como por la mayor propensión de los mismos a aceptar empleos de menor calidad.

De lo expuesto se desprende -con las limitaciones derivadas de la carencia de información para el año 2003-, que la cantidad de habitantes de origen chaqueño que habrían arribado y permanecido en el Gran Rosario en los últimos cinco años es irrisoria (el 95\% de los mismos ya residían en la región antes del $1^{\circ}$ trimestre de 2002) y la cantidad de puestos de trabajo a los cuales habrían accedido es estadísticamente nula $\left(0,1 \%\right.$ de los ocupados del aglomerado en el $1^{\circ}$ trimestre de 2007), en tanto su volumen total no parecería constituir un problema mayor para la situación ocupacional del área, lo que demostraría que el argumento esgrimido contra la migración de los nativos de esa provincia, más allá del juicio de valor que pueda merecer, es empíricamente inexacto.

\section{La calidad del empleo asalariado}

\section{a) Tipo de empleo}

El $86 \%$ de los 73.000 puestos de trabajo en relación de dependencia creados entre 2003 y 2007 constituyen ocupaciones permanentes frente a sólo un 3\% de oportunidades laborales transitorias (63.000 y 2.000 empleos respectivamente), correspondiéndole el resto a posiciones asalariadas en el servicio doméstico, las que, por las características propias de estas actividades no pueden incluirse en ninguna de las categorías anteriores.

A su vez, el empleo asalariado "fraudulento" -presente tanto en el sector público como privado-, que remite a modalidades que buscan ocultar la existencia de una relación de dependencia con el empleador, experimentó un marcado retroceso, reduciendo su magnitud al $60 \%$ de la existente tres años y medio atrás.

\section{Cuadro XI}

\begin{tabular}{|c|c|c|c|c|c|c|}
\hline GRAN ROSARIO & \multicolumn{2}{|c|}{$3^{\circ}$ Trimestre 2003} & \multicolumn{2}{|c|}{$1^{0}$ Trimestre 2007} & \multicolumn{2}{|c|}{ Variaciones } \\
\hline & $\begin{array}{c}\text { Valores } \\
\text { absolutos }\end{array}$ & $\begin{array}{c}\text { Valores } \\
\text { porcentuales }\end{array}$ & $\begin{array}{c}\text { Valores } \\
\text { absolutos }\end{array}$ & $\begin{array}{c}\text { Valores } \\
\text { porcentuales }\end{array}$ & $\begin{array}{c}\text { Valores } \\
\text { absolutos }\end{array}$ & $\begin{array}{c}\text { Valores } \\
\text { porcentuales }\end{array}$ \\
\hline $\begin{array}{l}\text { Tipo de ocupación principal de los asalariados } \\
\text { Asalariados permanentes } \\
\text { Asalariados transitorios } \\
\text { Servicio doméstico } \\
\text { Asalariados "fraudulentos" }\end{array}$ & \begin{tabular}{r|}
287.822 \\
202.016 \\
53.679 \\
23.889 \\
8.239 \\
\end{tabular} & $\begin{array}{r}\mathbf{1 0 0 , 0 \%} \\
70,2 \% \\
18,6 \% \\
8,3 \% \\
2,9 \% \\
\end{array}$ & $\begin{array}{r}360.890 \\
264.892 \\
55.882 \\
35.223 \\
4.893 \\
\end{array}$ & $\begin{array}{r}\mathbf{1 0 0 , 0 \%} \\
73,4 \% \\
15,5 \% \\
9,8 \% \\
1,4 \% \\
\end{array}$ & \begin{tabular}{r|}
73.068 \\
62.876 \\
2.204 \\
11.334 \\
-3.346 \\
\end{tabular} & $\begin{array}{r}\mathbf{2 5 , 3 9 \%} \\
31,12 \% \\
4,11 \% \\
47,44 \% \\
-40,61 \% \\
\end{array}$ \\
\hline
\end{tabular}

Fuente: Elaboración propia a partir de la EPH continua (Base Usuaria Ampliada)

\section{b) Acceso a los beneficios sociales}

Mientras el 98\% de los nuevos ocupados en calidad de obreros o empleados (71.000 personas) gozan de la totalidad de los beneficios correspondientes a su status laboral (vacaciones pagas, aguinaldo, licencia por enfermedad y obra social) y el $14 \%$ (equivalente a unos 10.000 puestos de trabajo) cuentan con al menos 
uno de ellos, los trabajadores en relación de dependencia que carecen de la totalidad de los mismos experimentó una ligera disminución.

\section{Cuadro XII}

\begin{tabular}{|c|c|c|c|c|c|c|}
\hline GRAN ROSARIO & \multicolumn{2}{|c|}{$3^{\circ}$ Trimestre 2003} & \multicolumn{2}{|c|}{$1^{\circ}$ Trimestre 2007} & \multicolumn{2}{|c|}{ Variaciones } \\
\hline & $\begin{array}{c}\text { Valores } \\
\text { absolutos }\end{array}$ & $\begin{array}{c}\text { Valores } \\
\text { porcentuales }\end{array}$ & $\begin{array}{c}\text { Valores } \\
\text { absolutos }\end{array}$ & $\begin{array}{c}\text { Valores } \\
\text { porcentuales }\end{array}$ & $\begin{array}{c}\text { Valores } \\
\text { absolutos }\end{array}$ & $\begin{array}{c}\text { Valores } \\
\text { porcentuales }\end{array}$ \\
\hline
\end{tabular}

Fuente: Elaboración propia a partir de la EPH continua (Base Usaria Ampliada)

Como consecuencia de esta evolución, la estructura ocupacional asalariada exhibe en 2007 un perfil que, si bien dista mucho de poder considerarse satisfactorio (sólo el 63\% de los obreros y empleados pueden disfrutar de la totalidad de estos beneficios y tres de cada diez no tiene acceso a ninguno), resulta significativamente mejor que el existente tres años y medio atrás.

Como era, a priori, esperable, la mayor proporción de ocupados en relación de dependencia que gozan de todos los beneficios corresponde a aquellos con una ocupación permanente y la menor a los que trabajan en el servicio doméstico. ${ }^{20}$

Asimismo se comprueba que existe una relación directa entre la proporción de asalariados que tienen acceso a la totalidad de esos derechos y el tamaño del establecimiento en el cual trabajan: en tanto en aquellos de más de 40 ocupados dicha proporción superaba en el $1^{\circ}$ trimestre de 2007 el $90 \%$, en las microempresas se reducía a alrededor de un tercio del plantel de trabajadores. Asimismo, mientras en las primeras menos del $6 \%$ carecía de la totalidad de estos derechos, en las últimas esa cifra alcanzaba al 56\%.

Por último, cabe agregar que el porcentaje de los trabajadores en relación de dependencia que gozan de la totalidad de estos beneficios es más reducido en la rama de actividad que ha experimentado un notable crecimiento en el período bajo análisis, y sobre cuya evolución se depositaban buena parte de las expectativas de mejoramiento de la situación ocupacional de la región (construcción) ${ }^{21}$, seguida por la que concentra la mayor proporción de asalariados (sector terciario, incluido el servicio doméstico).

En efecto, en la primera sólo el $40 \%$ de los asalariados se encuentra en esa situación, proporción que en la segunda supera el $60 \%$ de los mismos, en tanto en el sector manufacturero alcanza el $75 \%$. 


\section{Cuadro XIII}






\section{c) El empleo no registrado}

De los nuevos empleados y obreros se le efectúan descuentos jubilatorios a un porcentaje similar al de aquellos que gozan de todos los beneficios sociales, con lo cual la proporción de los que aún permanecen "en negro" descendió del 45 al $36 \%$ en estos 42 meses.

Esta evolución positiva no deja de resultar, sin embargo, absolutamente insatisfactoria, toda vez que revela que después de tres años medio de un crecimiento económico sin precedentes, más de un tercio de los asalariados (130.000 trabajadores) todavía no tiene acceso a los derechos previsionales correspondientes a su categoría ocupacional.

\section{Cuadro XIV}

\begin{tabular}{|c|c|c|c|c|c|c|}
\hline \multirow[t]{2}{*}{ GRAN ROSARIO } & \multicolumn{2}{|c|}{$3^{\circ}$ Trimestre 2003} & \multicolumn{2}{|c|}{$1^{\circ}$ Trimestre 2007} & \multicolumn{2}{|c|}{ Variaciones } \\
\hline & $\begin{array}{l}\text { Valores } \\
\text { absolutos }\end{array}$ & $\begin{array}{c}\text { Valores } \\
\text { porcentuales }\end{array}$ & $\begin{array}{c}\text { Valores } \\
\text { absolutos }\end{array}$ & $\begin{array}{c}\text { Valores } \\
\text { porcentuales }\end{array}$ & $\begin{array}{c}\text { Valores } \\
\text { absolutos }\end{array}$ & $\begin{array}{c}\text { Valores } \\
\text { porcentuales }\end{array}$ \\
\hline $\begin{array}{l}\text { Asalariados sin descuento jubilatorio } \\
\text { Asalariados con descuento jubilatorio }\end{array}$ & $\begin{array}{l}128.655 \\
159.167\end{array}$ & $\begin{array}{l}44,7 \% \\
55,3 \%\end{array}$ & $\begin{array}{l}130.496 \\
230.394\end{array}$ & $\begin{array}{l}36,2 \% \\
63,8 \%\end{array}$ & $\begin{array}{r}1.841 \\
71.227\end{array}$ & $\begin{array}{r}1,43 \% \\
44,75 \%\end{array}$ \\
\hline
\end{tabular}

Fuente: Elaboración propia a partir de la EPH continua (Base Usuaria Ampliada)

Cabe hacer notar que la existencia de este fenómeno no sólo implica una violación a la normativa vigente que se traduce en un alto nivel de desprotección de los trabajadores afectados y su grupo familiar, sino que requiere asimismo -al menos en una alta proporción de los casos-, la no declaración por parte de la unidad productiva en la cual se desempeñan de un volumen de ingresos de magnitud al menos similar a la necesaria para abonar sus sueldos y salarios, lo que implica que una proporción indeterminada pero, a priori, no desdeñable de la riqueza generada en el aglomerado está evadiendo las correspondientes obligaciones tributarias sobre su facturación.

En principio, resultaría confirmatorio de esta aseveración el hecho de que una elevada $-\mathrm{y}$ creciente- proporción de los asalariados no recibe ni entrega comprobante de pago alguno por el trabajo realizado, lo cual, excepto en el caso del servicio doméstico (donde nueve de cada diez ocupados se encuentran en esa situación) $\mathrm{y}$, eventualmente, el segmento de microestablecimientos con un número muy reducido de empleados, la remuneración del resto de la mano de obra afectada por este fenómeno sólo puede ser realizada con ingresos no declarados por el empleador.

Como en el caso de los beneficios analizados anteriormente, la mayor proporción de ocupados en relación de dependencia a los que se les efectúa el descuento jubilatorio corresponde a aquellos con una ocupación permanente ( $86 \%$ ) y la menor a los trabajadores del servicio doméstico (10,3\%).

Enformaanáloga,seconstatalaexistenciadeunarelacióninversaentrelaproporción de asalariados "en negro" y el tamaño del establecimiento en el cual trabajan: mientras en las microempresas casi el $70 \%$ se encontraba en esa situación, en las unidades 
de porte intermedio el porcentaje se reducía al 25\% y en las de mayor dimensión la cifra caía al $6,9 \%$, es decir, una décima parte del valor correspondiente a las primeras.

\section{Cuadro XV}

\begin{tabular}{|c|c|c|c|c|c|c|}
\hline GRAN ROSARIO & \multicolumn{2}{|c|}{$3^{\circ}$ Trimestre 2003} & \multicolumn{2}{|c|}{$1^{\circ}$ Trimestre 2007} & \multicolumn{2}{|c|}{ Variaciones } \\
\hline & $\begin{array}{c}\text { Valores } \\
\text { absolutos }\end{array}$ & $\begin{array}{c}\text { Valores } \\
\text { porcentuales }\end{array}$ & $\begin{array}{c}\text { Valores } \\
\text { absolutos }\end{array}$ & $\begin{array}{c}\text { Valores } \\
\text { porcentuales }\end{array}$ & $\begin{array}{c}\text { Valores } \\
\text { absolutos }\end{array}$ & $\begin{array}{c}\text { Valores } \\
\text { porcentuales }\end{array}$ \\
\hline $\begin{array}{l}\text { Comprobante de pago de los asalariados } \\
\text { No le dan ni entrega nada } \\
\text { No cobra (trabajador sin pago/ad } \\
\text { Resto de los asalariados (1) }\end{array}$ & $\begin{array}{r}\mathbf{2 8 7 . 8 2 2} \\
80.358 \\
1.684 \\
205.780\end{array}$ & $\begin{array}{r}\mathbf{1 0 0 , 0 \%} \\
27,9 \% \\
0,6 \% \\
71,5 \%\end{array}$ & $\begin{array}{r}\mathbf{3 6 0 . 8 9 0} \\
109.331 \\
1.259 \\
250.300\end{array}$ & $\begin{array}{r}\mathbf{1 0 0 , 0 \%} \\
30,3 \% \\
0,3 \% \\
69,4 \%\end{array}$ & $\begin{array}{r}73.068 \\
28.974 \\
-425 \\
44.519 \\
\end{array}$ & \begin{tabular}{r|}
$\mathbf{2 5 , 3 9 \%}$ \\
$36,06 \%$ \\
$-25,21 \%$ \\
$21,63 \%$
\end{tabular} \\
\hline
\end{tabular}

(1) Incluidos los cuenta propia con un solo cliente.

Fuente: Elaboración propia a partir de la EPH continua (Base Usuaria Ampliada)

\section{Cuadro XVI}

\begin{tabular}{|c|c|c|c|}
\hline GRAN ROSARIO & $\begin{array}{c}\text { 3er } \\
\text { Trimestre } \\
2003\end{array}$ & $\begin{array}{c}\text { 1er } \\
\text { Trimestre } \\
2007\end{array}$ & Variaciones \\
\hline $\begin{array}{l}\text { Asalariados con descuento jubilatorio según tipo } \\
\text { de ocupación principal }\end{array}$ & $\begin{array}{c}\text { Valores } \\
\text { porcentuales }\end{array}$ & $\begin{array}{c}\text { Valores } \\
\text { porcentuales }\end{array}$ & $\begin{array}{l}\text { (En puntos } \\
\text { porcentuales) }\end{array}$ \\
\hline Asalariados permanentes & $100,0 \%$ & $100,0 \%$ & \\
\hline Sin descuento jubilatorio & $17,9 \%$ & $14,1 \%$ & $-3,8$ \\
\hline Con descuento jubilatorio & $82,1 \%$ & $85,9 \%$ & 3,8 \\
\hline Asalariados transitorios & $100,0 \%$ & $100,0 \%$ & \\
\hline Sin descuento jubilatorio & $82,8 \%$ & $83,3 \%$ & 0,6 \\
\hline Con descuento jubilatorio & $17,2 \%$ & $16,7 \%$ & $-0,6$ \\
\hline Servicio doméstico & $100,0 \%$ & $100,0 \%$ & \\
\hline Sin descuento jubilatorio & $93,5 \%$ & $89,7 \%$ & $-3,8$ \\
\hline Con descuento jubilatorio & $6,5 \%$ & $10,3 \%$ & 3,8 \\
\hline Asalariados de establecimientos de hasta 5 & $100,0 \%$ & $100,0 \%$ & \\
\hline $\begin{array}{l}\text { ocupados } \\
\text { Sin descuento jubilatorio }\end{array}$ & $719 \%$ & $100,0 \%$ & \\
\hline $\begin{array}{l}\text { Sin descuento jubilatorio } \\
\text { Con descuento jubilatorio }\end{array}$ & $\begin{array}{l}71,9 \% \\
28,1 \%\end{array}$ & $68,9 \%$ & $-3,0$ \\
\hline Asalariados de establecimientos de 6 a 40 & $28,1 \%$ & $31,1 \%$ & 3,0 \\
\hline ocupados & $100,0 \%$ & $100,0 \%$ & \\
\hline Sin descuento jubilatorio & $42,1 \%$ & $25,0 \%$ & $-17,2$ \\
\hline Con descuento jubilatorio & $57,9 \%$ & $75,0 \%$ & 17,2 \\
\hline Asalariados de establecimientos de más de 40 & $1000 \%$ & $1000 \%$ & \\
\hline $\begin{array}{l}\text { ocupados } \\
\text { Sin descuento jubilatorio }\end{array}$ & $117 \%$ & 100,070 & \\
\hline uento jubilatorio & $88,3 \%$ & $93,1 \%$ & 4,7 \\
\hline Asalariados del servicio doméstico & $100,0 \%$ & $100,0 \%$ & \\
\hline Sin descuento jubilatorio & $93,5 \%$ & $89,7 \%$ & $-3,8$ \\
\hline Con descuento jubilatorio & $6,5 \%$ & $10,3 \%$ & 3,8 \\
\hline Asalariados del sector primario & $100,0 \%$ & $100,0 \%$ & \\
\hline Sin descuento jubilatorio & $86,3 \%$ & $39,9 \%$ & $-46,4 \%$ \\
\hline Con descuento jubilatorio & $13,7 \%$ & $60,1 \%$ & $46,4 \%$ \\
\hline Asalariados del sector manufacturero & $100,0 \%$ & $100,0 \%$ & \\
\hline Sin descuento jubilatorio & $35,7 \%$ & $25,9 \%$ & $-9,9 \%$ \\
\hline Con descuento jubilatorio & $64,3 \%$ & $74,1 \%$ & $9,9 \%$ \\
\hline Asalariados de la construcción & $100,0 \%$ & $100,0 \%$ & \\
\hline Sin descuento jubilatorio & $63,5 \%$ & $56,4 \%$ & $-7,0 \%$ \\
\hline Con descuento jubilatorio & $36,5 \%$ & $43,6 \%$ & $7,0 \%$ \\
\hline Asalariados del sector servicios & $100,0 \%$ & $100,0 \%$ & \\
\hline Sin descuento jubilatorio & $43,3 \%$ & $36,4 \%$ & $-6,9 \%$ \\
\hline Con descuento jubilatorio & $56,7 \%$ & $63,6 \%$ & $6,9 \%$ \\
\hline
\end{tabular}

Fuente: Elaboración propia a partir de la EPH continua (Base Usuaria Ampliada) 
A nivel de ramas de actividad ${ }^{22}$ se reproduce también lo observado en relación con los beneficios de que gozan los asalariados: el porcentaje más elevado de empleo no registrado corresponde a la construcción $(56,4 \%)$ seguido por los servicios $(36,4 \%)$, en tanto en el sector manufacturero esa proporción desciende marcadamente para ubicarse en el 25,9\%.

Paralelamente se advierte que la totalidad de los nuevos asalariados a los que no se le efectúan los correspondientes descuentos previsionales han optado por paliar esta situación a través de la realización de aportes jubilatorios, no obstante lo cual, a comienzos de 2007 una tercera parte de los ocupados en relación de dependencia aún seguía sin poseer cobertura del sistema de seguridad social, lo que implica que en ese momento existían unos 120.000 trabajadores que carecían de la posibilidad de obtener ingresos a través del mismo en caso de retirarse de sus puestos de trabajo, sea por razones de edad o cuestiones de incapacidad.

\section{Cuadro XVII}

\begin{tabular}{|c|c|c|c|c|c|c|}
\hline GRAN ROSARIO & \multicolumn{2}{|c|}{ 3er Trimestre 2003} & \multicolumn{2}{|c|}{ 1er Trimestre 2007} & \multicolumn{2}{|c|}{ Variaciones } \\
\hline & $\begin{array}{r}\text { Valores } \\
\text { absolutos }\end{array}$ & $\begin{array}{c}\text { Valores } \\
\text { porcentuales }\end{array}$ & $\begin{array}{c}\text { Valores } \\
\text { absolutos }\end{array}$ & $\begin{array}{c}\text { Valores } \\
\text { porcentuales }\end{array}$ & $\begin{array}{c}\text { Valores } \\
\text { absolutos }\end{array}$ & $\begin{array}{c}\text { Valores } \\
\text { porcentuales }\end{array}$ \\
\hline $\begin{array}{l}\text { Asalariados según cobertura previsional } \\
\text { Asalariados con descuento jubilatorio } \\
\text { Asalariados con aporte jubilatorio } \\
\text { Asalariados sin aporte jubilatorio }\end{array}$ & $\begin{array}{r}\mathbf{2 8 7 . 8 2 2} \\
159.167 \\
6.705 \\
121.950\end{array}$ & $\begin{array}{r}100,0 \% \\
55,3 \% \\
2,3 \% \\
42,4 \%\end{array}$ & $\begin{array}{r}360.890 \\
230.394 \\
10.114 \\
120.382\end{array}$ & $\begin{array}{r}100,0 \% \\
63,8 \% \\
2,8 \% \\
33,4 \%\end{array}$ & $\begin{array}{r}73.068 \\
71.227 \\
3.409 \\
-1.568\end{array}$ & $\begin{array}{l}25,39 \% \\
44,75 \% \\
50,84 \% \\
-1,29 \%\end{array}$ \\
\hline
\end{tabular}

(1) Redistribuidos los cuenta propia en un solo cliente.

Fuente: Elaboración propia a partir de la EPH continua (Base Usuaria Ampliada)

\section{La evolución del salario}

La evolución del salario real da cuenta, ceteris paribus ${ }^{23}$, de los cambios registrados en las condiciones materiales de vida de todos aquellos que directa (obreros y empleados) o indirectamente (miembros de la unidad familiar que dependen económicamente de ellos) han experimentado en el período.

Durante el mismo, el salario nominal promedio en la ocupación principal creció el $112 \%$, pasando de $\$ 491,60$ a $\$ 1.041,59$. Considerando que en ese lapso el Indice de Precios al Consumidor aumentó en torno al 34,5\% $\%^{24}$, en el $1^{\circ}$ trimestre de 2007 el ingreso promedio de los trabajadores en relación de dependencia les permitía adquirir cerca de un $58 \%$ más de bienes y servicios que tres años y medio atrás.

Complementariamente, comparando los salarios nominales medios de cada una de las ondas con los respectivos valores de la Canasta Básica Total (CBT) ${ }^{25}$, se comprueba que la "capacidad de subsistencia" de los mismos registra un incremento proporcionalmente aún más acentuado que el correspondiente a los ingresos reales $(61,1 \%)$, pasando de un monto equivalente a 2,18 CBT a uno de 3,51 . En consecuencia, mientras en el $3^{\circ}$ trimestre de 2003 el salario promedio de la ocupación principal sólo alcanzaba a cubrir dos terceras partes de las necesidades elementales de una "familia tipo"26, a comienzos de 2007 llegaba a superar ligeramente la satisfacción de la totalidad de las mismas ${ }^{27}$, con lo cual se advierte que la mejoría experimentada por la remuneración media de un trabajador en relación de dependencia era suficiente para que su grupo familiar pudiera superar la Línea de Pobreza. ${ }^{28}$ 
Cuadro XVIII

\begin{tabular}{|l|c|c|r|r|}
\hline GRAN ROSARIO & \multicolumn{1}{c|}{$\begin{array}{c}\text { 3er } \\
\text { Trimestre } \\
\text { Trimestre } \\
\mathbf{2 0 0 3}\end{array}$} & \multicolumn{2}{|c|}{ Variaciones } \\
\hline Ingreso de los asalariados en la ocupación & Valores & Valores & Valores & Valores \\
principal & absolutos & absolutos & absolutos & porcentuales \\
\cline { 2 - 5 } Ingreso promedio en pesos corrientes (1) & 491,60 & $1.041,59$ & 550,0 & $111,88 \%$ \\
Ingreso promedio real (2) & 100,0 & 157,59 & 57,6 & $57,59 \%$ \\
Capacidad de subsistencia promedio(3) & 2,18 & 3,51 & 1,33 & $61,12 \%$ \\
\hline
\end{tabular}

(1) Solo los que declararon ingresos.

(2) Ingreso nominal deflactado por el IPC - Base $3^{\circ}$ Trimestre de $2003=100$

(3) En Canastas Básicas Totales.

Fuente: Elaboración propia a partir de la EPH continua (Base Usuaria Ampliada)

\section{La participación de los asalariados en el incremento del Produc- to Geográfico del Aglomerado. Un intento de estimación a partir de la información disponible}

De acuerdo a la información suministrada por la EPH, entre 2003 y 2007 la masa salarial se habría prácticamente duplicado ${ }^{29}$, con un aumento porcentual superior al estimado para el Producto Bruto Regional ${ }^{30}$, dando lugar a una redistribución del ingreso entre el capital y el trabajo, de modo tal que a comienzos de 2007 la participación de los salarios en el producto del Gran Rosario habría aumentado entre un $53 \%$ y un $65 \%$ respecto del valor correspondiente al $3^{\circ}$ trimestre de $2003^{31}$, según la hipótesis de crecimiento del PBG que se escoja.

\section{Cuadro XIX}

\begin{tabular}{|l|r|r|}
\hline GRAN ROSARIO & $\begin{array}{c}\text { 3er } \\
\text { Trimestre } \\
\mathbf{2 0 0 3}\end{array}$ & $\begin{array}{c}\text { 1er } \\
\text { Trimestre } \\
\mathbf{2 0 0 7}\end{array}$ \\
\hline Variación de la participación de los salarios en & & \\
el PBG & & \\
Indice Base 3er Trimestre de 2003=100) & 100,0 & 157,6 \\
Salario real medio (1) & 100,0 & 125,4 \\
Cantidad de asalariados (2) & 100,0 & 197,6 \\
Masa salarial & 100,0 & 124,5 \\
PBG - Hipótesis I(3) & 100,0 & 129,4 \\
PBG - Hipótesis II (4) & 100,0 & 119,6 \\
PBG - Hipótesis III (5) & & \\
Participación de los salarios en el PBG & 100,0 & 158,8 \\
Hipótesis I & 100,0 & 152,8 \\
Hipótesis II & 100,0 & 165,3 \\
Hipotesis III & \multicolumn{2}{|c}{} \\
\hline
\end{tabular}

(1) Salario real medio en la ocupación principal.

(2) Asalariados totales (incluye a los asalariados "fraudulentos").

(3) Variación del PBI no primario a precios de 1993, INDEC.

(4) $120 \%$ de la variación del PBI no primario a precios de 1993, INDEC.

(5) $80 \%$ de la variación del PBI no primario a precios de 1993, INDEC.

Fuente: Elaboración propia a partir de la EPH continua (Base Usuaria Ampliada) e INDEC, Producto Interno Bruto a precios de mercado, Serie Empalmada 1980 - 2005. 


\section{A modo de cierre: el impacto del comportamiento del mercado de trabajo en las condiciones materiales de vida de la población}

El abordaje convencional de las cuestiones relacionadas con el empleo y la pobreza establece -explícita o implícitamente- una suerte de frontera temática según la cual las primeras remiten al análisis de la estructura y funcionamiento del aparato productivo, en tanto las segundas se refieren al ámbito más amplio de lo que suele denominarse "la cuestión social", aproximación que sugiere, a su vez, la existencia de dos planos independientes de resolución de estos problemas: el de la política económica para atender las tensiones del mercado de trabajo y -subsidiariamente- el de las políticas sociales para hacerse cargo de los problemas de la exclusión. ${ }^{32}$

La vinculación entre el ámbito de la actividad económica y el de las condiciones materiales de vida permite, en cambio, constatar que el crecimiento de la ocupación y los salarios tuvo un notable impacto en la reducción de la población afectada por la imposibilidad de acceder a la satisfacción de sus necesidades más elementales. En el primer semestre de 2007 el número de personas que se ubicaban por debajo de la Línea de Pobreza se había reducido a menos del $40 \%$ de las que se encontraban en esa situación en el extremo inicial del período, lo que implica que alrededor de 345.000 habitantes de la región consiguieron salir de la condición de privación absoluta en que se hallaban tres años y medio atrás, reduciendo la proporción de la población del aglomerado cuyos ingresos familiares aún no le permitían superar la LP en alrededor de 30 puntos porcentuales, del 47,9 al 18,3\%.33

La indigencia, por su parte, evolucionó en igual sentido pero de manera proporcionalmente más intensa, reduciéndose en alrededor de 215.000 la cantidad de personas afectadas por esta forma extrema de carencia material (cifra que equivale a una disminución superior al 75\%), con lo cual, mientras en la segunda mitad de 2003 prácticamente uno de cada cuatro habitantes del Gran Rosario no podía siquiera alimentarse adecuadamente, en el extremo final del período esa proporción se había reducido a uno de cada veinte..$^{34}$

\section{Cuadro XX}

\begin{tabular}{|c|c|c|c|c|}
\hline GRAN ROSARIO & $\begin{array}{c}\text { 2do Semestre } \\
2003\end{array}$ & $\begin{array}{c}\text { 1er Semestre } \\
2007\end{array}$ & \multicolumn{2}{|c|}{ Variaciones } \\
\hline $\begin{array}{l}\text { Población por debajo de la Línea de } \\
\text { Pobreza e Indigencia }\end{array}$ & $\begin{array}{c}\text { Valores } \\
\text { absolutos }\end{array}$ & $\begin{array}{c}\text { Valores } \\
\text { absolutos }\end{array}$ & $\begin{array}{c}\text { Valores } \\
\text { absolutos }\end{array}$ & $\begin{array}{c}\text { Valores } \\
\text { porcentuales }\end{array}$ \\
\hline $\begin{array}{l}\text { Línea de Pobreza (1) } \\
\text { Línea de Indigencia (1) }\end{array}$ & $\begin{array}{l}562.622 \\
280.724\end{array}$ & $\begin{array}{r}217.922 \\
65.496\end{array}$ & $\begin{array}{l}-344.700 \\
-215.228\end{array}$ & $\begin{array}{l}-61,27 \% \\
-76,67 \%\end{array}$ \\
\hline $\begin{array}{l}\text { Línea de Pobreza (2) } \\
\text { Línea de Indigencia (2) }\end{array}$ & $\begin{array}{l}47,9 \% \\
23,9 \%\end{array}$ & $\begin{array}{r}18,3 \% \\
5,5 \%\end{array}$ & $\begin{array}{l}-29,6 \text { p.p. } \\
-18,4 \text { p.p. }\end{array}$ & $\begin{array}{l}-61,80 \% \\
-76,99 \%\end{array}$ \\
\hline
\end{tabular}

(1) En número de personas.

(2) Como porcentaje de la población total.

Fuente: Elaboración propia en base a INDEC (2007). 
De todas maneras, para esa fecha aún quedaban más de 200.000 residentes del aglomerado que se encontraban en condiciones de pobreza - con una fuerte participación de niños y adolescentes (Robin y Duran, 2006)-, 65.000 de los cuales (el $30 \%$ ) se ubicaban en el estrato más bajo de insatisfacción de sus necesidades materiales (indigentes), mostrando que aún queda un largo camino para dejar atrás, definitivamente, el purgatorio.

\section{Referencias}

1. En este sentido, la gestión de Néstor Kirchner aprovechó las graves circunstancias que atravesaba la Argentina en el momento de su asunción para llevar a cabo una serie de medidas tendientes a ampliar los márgenes de maniobra del país en el marco de una política de reparación social, cuya característica más relevante, como señala Natanson (2004) en el Prólogo de su libro, fue “...la capacidad de romper el discurso dominante de la última década, que acotaba los márgenes de maniobra a la administración de la cosa pública, y reubicar a la política en el centro. Kirchner sacó a la política del desfiladero estrecho por el que discurrió durante los ' 90 y amplió el campo de lo posible. Hizo lo que se pensaba que no se podía hacer". (la bastardilla es nuestra).

2. Para las EPH puntuales, en el Aglomerado Gran Rosario se había detectado la existencia de un factor de estacionalidad en la tasa de desocupación -positivo para la onda de mayo y negativo para la de octubre- del orden del 7,6\%, lo que implicaba - dado el carácter bianual de las mediciones- que, entre dos ondas sucesivas, la variación atribuible a este componente se ubicaba en torno del $15 \%$. El mismo habría estado asociado a una ligera estacionalidad de análogo perfil en la tasa de actividad y una variación de la tasa de empleo de signo opuesto, también leve aunque necesariamente de intensidad algo mayor que la primera (Crucella, 2000). Dado que la aplicación del nuevo marco metodológico es muy reciente, no se cuenta aún con un número de observaciones suficiente que permita confirmar la presencia de una distorsión estacional en los datos que provee la EPH continua.

3. Para un análisis histórico de la evolución de la estructura productiva de la región, ver Municipalidad de Rosario (1971: Capítulos 1 y 2) y Rofman (1997: 86-91).

4. La discusión acerca de si dicha ruptura fue una consecuencia necesaria del "agotamiento" de ese modelo de desarrollo, o si la misma respondió a la necesidad de reconfigurar la estructura socioeconómica del país vía el "disciplinamiento" de sus actores sociales, excede los límites de este artículo así como -lamentablemente-los conocimientos de su autor quien, de todas maneras, se inclina por la segunda hipótesis.

5. En el primer semestre de 2002 la tasa de desocupación abierta alcanzó la cifra record de 24,3\%, superando en 2,8 puntos porcentuales el valor de la correspondiente al total de los aglomerados relevados y en 3,1 p.p. al del conjunto de aquellos ubicados en el interior del país, en tanto 640.000 habitantes del área se ubicaban por debajo de la línea de pobreza $(54,6 \%$ de la población total) y tres de cada diez no alcanzaban siquiera a satisfacer sus necesidades alimentarias (343.000 personas) (INDEC, 2007).

6. Estimada a partir de la tasa de variación intercensal promedio 1991-2001 (INDEC, 2001). Al respecto, cabe hacer notar que, aún cuando a lo largo del período 1960-1991 la tasa promedio anual a la cual evolucionó la población del área muestra una tendencia claramente decreciente $(1,86 \%$ anual acumulativo para el lapso que medió entre los CNPV $1960-70$ y $1,74 \%$ y $1,48 \%$ para los intervalos intercensales 1970-1980 y 1980-1991, respectivamente) (Lindenboim, 1997), no deja de resultar llamativa la notable contracción que la misma experimentó entre los extremos de la última década, durante la cual el ritmo de variación $(0,39 \%$ anual) (INDEC, 2001) equivale a la cuarta parte del correspondiente al período intercensal precedente. Por otra parte, es dable comprobar que de los 25 aglomerados relevados por la EPH a comienzos de 1991, el Gran Rosario es el que registra la tasa de variación poblacional más baja para el período 1991-2001, lo que sugeriría la posibilidad de que, en algún momento del mismo - probablemente hacia finales de ese decenio-, haya tenido lugar un proceso migratorio de parte de la población del aglomerado en busca de mejores condiciones de inserción en el aparato productivo, fenómeno que si bien excede los límites del presente artículo, no deja de constituir 
un elemento básico de la oferta laboral local -a través de su volumen y composición etaria-, que ameritaría ser analizado con mayor profundidad.

En este sentido es conocida la influencia que el comportamiento del mercado de trabajo (vía diferenciales de ingreso y probabilidades de inserción laboral respecto a los lugares de origen o residencia) tiene sobre los flujos migratorios (Beccaria, 1980: 179-181) tanto internos como desde/hacia otros países, especialmente los limítrofes, por lo cual no es, a priori, improbable, que a partir de 2003, con la notable mejora experimentada por la situación del empleo y los salarios en el Gran Rosario, se haya revertido en alguna medida el sentido de esta corriente migratoria y el ritmo de crecimiento poblacional de la región haya experimentado un aumento respecto del registrado en la década precedente, alimentado fundamentalmente, al menos en sus comienzos, por migrantes internos.

Por lo tanto, la reexpansión de la población en base a la tasa de crecimiento -promedio- que tuvo la misma durante el período intercensal 1991-2001 podría, en principio, estar subestimando la correspondiente al período analizado, afectando en el mismo sentido los valores absolutos de las variables y atributos analizados y, consecuentemente, las magnitudes -absolutas y relativas- de las variaciones registradas.

7. A lo largo del presente artículo se emplean, como es de uso generalizado, los términos ocupaciones, empleos, puestos de trabajo y oportunidades laborales como sinónimos de ocupados o personas incorporadas al circuito productivo cuando, en rigor, no son exactamente equivalentes. Dado que la población ocupada es el "conjunto de personas que tiene por lo menos una ocupación" (INDEC, 1997a) el número de ocupaciones o puestos de trabajo siempre será mayor o, a lo sumo, igual al de ocupados.

En el Gran Rosario, en el período bajo análisis, la cantidad de empleos creció más acentuadamente que el de personas ocupadas: los puestos de trabajo aumentaron el 21,2\% (alrededor de 100.000 nuevas oportunidades laborales), fenómeno que se refleja en el hecho de que la proporción de personas que posee más de una inserción en el circuito productivo haya pasado del 5,9 al 7,8\%, lo que implica que unos 13.000 habitantes del aglomerado tuvieron posibilidades de acceder a una o más ocupaciones adicionales.

8. Los beneficiarios del Plan Jefes y Jefas de Hogar Desocupados o cualquier otro similar sólo se consideran ocupados si realizan una contraprestación laboral por el mismo. En caso de recibir la ayuda económica sin llevar a cabo una tarea se consideran desocupados o inactivos, según las definiciones habituales.

9. El hecho de que en ambos períodos uno de cada cinco ocupados del Gran Rosario perteneciera al subconjunto de trabajadores de tiempo parcial que no desean dejar de serlo plantea la relevancia de incluir la creación de este tipo de posiciones laborales en la agenda de las políticas de empleo, en particular con vistas a satisfacer la necesidad de insertarse laboralmente de ciertos segmentos de la fuerza de trabajo que ven acotadas sus disponibilidades horarias por distintas razones.

10. Quienes suelen autoidentificarse como empleados estatales.

11. Considerándose como tales exclusivamente a aquellas en que trabajan hasta cinco personas.

12. Dada la reducida magnitud de los respectivos valores, particularmente del correspondiente a 2007 , así como la intensidad de la variación se recomienda utilizar estas cifras con precaución. Al respecto cabe hacer notar que en el caso de estimaciones simples (es decir, aquellas referidas a un único valor y no a un cociente entre valores), las inferiores a 60.000 casos cuentan con coeficientes de variación superiores al $10 \%$, por lo cual debe hacerse uso de ellas con cautela.

13. Resultado del incremento de unos 76.000 asalariados verdaderos y la disminución de alrededor de 3.000 asalariados "fraudulentos". Éstos comprenden a los trabajadores por cuenta propia que trabajan para un solo establecimiento y a los asalariados que entregan factura cuando cobran y a los cuales, en consecuencia, no se les hace el descuento jubilatorio. Por defecto, los "verdaderos" están constituidos por los restantes asalariados.

14. Lo reducido de las cifras en ambos casos obliga a utilizar estos datos con precaución (ver Nota 12).

15. Excepto en lo referido a la productividad de la fuerza de trabajo, lo antedicho presupone su incorporación en condiciones de asalariados registrados, cuyo volumen, si bien ha crecido en este período, sigue manteniéndose a niveles incompatibles con los estándares de una sociedad respetuosa de la normativa laboral vigente. 
16. Esa desagregación, si bien técnicamente factible, no ha sido incluida en este análisis por considerarse que la información que brinda resulta estadísticamente poco confiable.

17. Lo antedicho remite a la conveniencia de complementar el uso del indicador que mide la proporción en que varía el volumen de empleo en relación con una variación porcentual del producto (la elasticidad producto del empleo), con uno que haga lo propio con la relación entre la variación relativa de la cantidad total de horas trabajadas y la del producto (la elasticidad producto de las horas trabajadas).

18. La información correspondiente al lugar de origen y residencia 5 años atrás de la población sólo se encuentra disponible a partir del $4^{\circ}$ trimestre de 2004, por lo cual resulta imposible efectuar un análisis más preciso.

19. Se escogió este segmento etario ya que es aquél sobre el cual puede analizarse la situación ocupacional (ver supra).

20. Si bien el escaso -y decreciente- volumen de los asalariados "fraudulentos" impide realizar cualquier análisis sobre su situación, la persistencia en ambos años de las proporciones de sus integrantes de acuerdo a la percepción de los beneficios correspondientes a los trabajadores en relación de dependencia sugeriría la existencia de una segmentación en el interior de este universo entre un subgrupo mayoritario que, mediante su aporte previsional en calidad de cuentapropistas y concesiones otorgadas por sus empleadores, cuentan de hecho con la totalidad de los mismos, mientras los restantes -entre los cuales se encontrarían los asalariados que no cobran (ver infra, Cuadro XV)- no poseen ninguno de ellos.

21. Se excluye de estas consideraciones al sector primario ya que por lo reducido de su magnitud la información que brinda resulta estadísticamente poco confiable.

22. Se excluye de estas consideraciones al sector primario ya que, por lo reducido de su magnitud, la información que brinda resulta estadísticamente poco confiable.

23. En rigor, los cambios de las condiciones materiales de vida de los hogares cuyos perceptores de ingresos son ocupados en relación de dependencia no depende exclusivamente de los registrados por los salarios reales sino también, entre otros factores, de los experimentados en la cantidad de asalariados pertenecientes al grupo familiar, de las variaciones registradas en la cantidad y composición de los totalidad de los integrantes de la unidad doméstica (dado que las necesidades de los mismos guardan relación con sus respectivos sexos y edades), así como de la evolución de la cantidad y calidad de los beneficios que las ocupaciones les brinden.

24. INDEC, Indice de Precios al Consumidor, Serie Histórica. Cabe hacer notar que el cambio en el cálculo de los valores de este indicador que dio origen a su cuestionamiento comenzó en enero de 2007, por lo cual el único subperíodo en el cual el mismo podría haber influido en la estimación de los salarios reales es el correspondiente al extremo final del intervalo temporal analizado $\left(1^{\circ}\right.$ trimestre de 2007). En consecuencia, aún cuando la subestimación del IPC hubiese sido muy grosera, no podría plausiblemente haber afectado el signo de la variación registrada por los mismos entre puntas, aunque obviamente sí su magnitud.

25. Su valor representa el monto de dinero necesario para que un varón de entre 30 y 59 años pueda satisfacer, por medio de la compra de bienes y servicios, un conjunto de necesidades alimentarias y no alimentarias consideradas esenciales, y constituye el límite por debajo del cual el mismo se encuentra en situación de pobreza. Para estimar el valor correspondiente a una unidad doméstica se debe recurrir al Método del Adulto Equivalente.

26. Constituida por un varón y una mujer de entre 30 y 59 años y dos menores (uno de cada sexo) de entre 10 y 12 años.

27. Un hogar de esas características requiere ingresos equivalentes a 3,30 CBT (INDEC, 2006).

28. Dado que la misma comprende tanto la correspondiente a los ocupados de tiempo completo como a los de jornada reducida, es más que plausible que en el caso de los primeros el ingreso medio superara con mayor holgura el valor de la CBT correspondiente a la unidad doméstica tomada como referencia.

29. Variación de la cual prácticamente el $70 \%$ corresponde al incremento de los salarios reales, en tanto el 30,6\% remite al incremento del número de trabajadores en relación de dependencia (redistribuido el efecto conjunto). 
30. Ante la carencia de información actualizada sobre el Producto Bruto Geográfico del Gran Rosario, se ha adoptado como una proxy de su evolución entre los extremos del período analizado la variación registrada en ese lapso por el PBI urbano (es decir, excluido el del sector primario), supuesto que no parecería, en principio, irrazonable, si se tiene en cuenta que, por las razones expuestas en la Introducción (ver supra), aún cuando el crecimiento porcentual del PBG del área pueda no haber sido exactamente coincidente con el del PBI urbano, no es dable esperar que sus respectivos valores hayan diferido significativamente. En este sentido, dado que la utilización de la variación de este último sólo debe ser tomada como una magnitud de referencia para poder estimar, tentativa e imperfectamente, la evolución de la porción de la riqueza generada en el Aglomerado durante el período analizado que le ha correspondido a los asalariados, se han considerado dos hipótesis alternativas: que el crecimiento del PBG del Gran Rosario haya sido un 20\% superior al del PBI urbano y que el mismo haya sido un $20 \%$ inferior.

31. La adopción del salario real medio de la ocupación principal supone que los ingresos correspondientes a ocupaciones adicionales en relación de dependencia experimentaron una variación de igual signo e intensidad.

32. "De ahí que se llegue casi por fatalidad a esta familiar dicotomía: la economía se preocupa del aumento de la producción y lo social se ocupa del reparto. O esta otra dicotomía, muy en boga pero no demasiado consistente: la economía se preocupa por la eficacia y el resto de las ciencias se ocupan de la justicia." (Méda, 1998: 176).

33. Dado que en el cálculo del valor de las canastas utilizadas para determinar tanto la Línea de Pobreza (CBT) como la de Indigencia (CBA) es necesario utilizar el Indice de Precios al Consumidor, si el IPC tiende a subestimar la variación de sus respectivos valores está haciendo lo propio con la población afectada por estas formas de carencia material absoluta, por lo cual la observación realizada en la Nota 24 queda relativizada por el hecho de que, en este caso, los datos de 2007 corresponden al primer semestre de ese año.

34. Esto no implica que el nivel de desigualdad en la distribución familiar del ingreso de la región haya disminuido en este período, ya que la reducción de los índices de pobreza y/o de indigencia no conllevan necesariamente una mejora en ese sentido.

\section{Bibliografía}

CABA (2001), Coyuntura económica de la ciudad de Buenos Aires $N^{o} 2$, "Nivel de instrucción y calificación laboral de los ocupados en la ciudad de Buenos Aires", Estudios Especiales, Buenos Aires.

L. BECCARIA(1980), "Los movimientos de corto plazo en el mercado de trabajo urbano y la coyuntura 1975-78 en la Argentina,” en Desarrollo Económico, Vol. 20, № 78, Buenos Aires.

C. CRUCELLA (2000), "La desocupación en el Gran Rosario durante la última década. Un intento de (re)interpretación", en Anuario del Departamento de Ciencias de la Comunicación, Volumen 5, Año 1999/00, Facultad de Ciencia Política y Relaciones Internacionales, Universidad Nacional de Rosario, Rosario.

(2003), “Convertibilidad, devaluación y después. Análisis y perspectivas de la situación ocupacional del Gran Rosario”, en Desarrollo y Región 2, Instituto de Desarrollo Regional, Rosario.

(2006), La duración de la jornada de trabajo: Estadísticas internacionales comparadas, SERIE JORNADA DE TRABAJO/2, PROYECTO DE APOYO AL PROGRAMA NACIONAL DE TRABAJO DECENTE, Oficina Internacional del Trabajo, Buenos Aires.

R. FRENKEL (2002), "Costos y beneficios de la Convertibilidad", en M. COHEN y M. GUTMAN (eds.), ¿Argentina en colapso? América Debate, IIED-The New School, Buenos Aires.

INDEC (1997a), ¿Cómo se mide el desempleo?, Buenos Aires.

(1997b), La calificación ocupacional y la educación formal entre 1991 y 1995: una relación

dificil?, Serie Estructura ocupacional No 4, primera y segunda parte, Buenos Aires.

(2001), Censo Nacional de Población, Hogares y Viviendas, Cuadro 12.1., Buenos Aires.

(2003a), Encuesta Permanente de Hogares (EPH). Cambios metodológicos, Buenos Aires.

(2003b), La nueva Encuesta Permanente de Hogares de Argentina, Buenos Aires. 
(2006), Incidencia de la pobreza y de la indigencia en 28 aglomerados urbanos, Resultados $2^{\circ}$ semestre 2005, Anexo Metodológico, Información de prensa, Buenos Aires.

(2007), Incidencia de la pobreza y de la indigencia en 31 aglomerados urbanos, Resultados $1^{\circ}$ semestre 2007, Información de prensa, Buenos Aires.

J. LINDENBOIM (1997), La población urbana argentina 1960-1991. Revisión Metodológica y resultados estadísticos, Cuadernos del CEPED N ${ }^{\circ} 1$, Centro de Estudios sobre Población, Empleo y Desarrollo, Buenos Aires.

D. MÉDA (1998), El trabajo. Un valor en peligro de extinción, Gedisa, Barcelona.

MUNICIPALIDAD DE ROSARIO (1971), Prediagnóstico de la estructura productiva del Área Gran Rosario, Comisión Coordinadora Urbanística, Ferroviaria, Vial y Portuaria para la ciudad de Rosario. J. NATANSON (2004), El presidente inesperado, Homo Sapiens Ediciones, Rosario.

S. ROBIN y P. DURAN (2006), "La evolución reciente de la pobreza por ingresos en el Gran Rosario y su impacto sobre los jóvenes”, en Acceso Directo, Año 1, N 1, Centro de la Juventud, Municipalidad de Rosario, Rosario.

A. ROFMAN (1997), Convertibilidad y desocupación en la Argentina de los '90, Colección CEACBC, Universidad de Buenos Aires, Buenos Aires.

Recibido: 30/03/09. Aceptado: 13/08/09. 